\title{
Women's attitude towards umbilical cord blood banking in Poland
}

Authors: Agata Pisula, Agnieszka Sienicka, Karolina Stachyra

Mentors: Joanna Kacperczyk-Bartnik MD, Agnieszka Dobrowolska-Redo MD PhD, Ewa RomejkoWolniewicz MD PhD

DOI: https://doi.org/10.26800/LV-142-supp5-40

Introduction:

Umbilical cord blood (UCB) is considered as a valuable potential source of hematopoietic stem and progenitor cells. A process of collecting and storing UCB in the immediate period after the birth is called UCB banking.

\section{Aim of the study:}

The study was conducted in order to determine women's knowledge, awareness, preferences and attitude towards UCB banking in Poland, considering the sociodemographic and obstetric factors.

\section{Material and Methods:}

A cross-sectional, self-administered, online questionnaire-based study including mostly multiple choice questions concerning attitude and awareness regarding UCB banking was conducted amongst women in Poland. A total of 1077 participants correctly completed the survey.

\section{Results:}

Most participants ( $n=911,84.6 \%$ ) were aware of the possibility of UCB banking. Social media were considered as the main source of information (47.5\%). However, the participants asked about their preferred source of reliable information mostly indicated the doctor $(86.8 \%)$. The majority of women $(61.8 \%)$ assessed their level of knowledge of UCB banking as still insufficient. Amongst the participants who supported UCB banking $(70 \%)$, the following reasons were considered as the most vital: potential possibility of helping their child (93.9\%) and helping other relatives (64.4\%). More than half of the respondents (66.9\%), who have not stored and are not willing to store their children's UCB, indicated the high cost of UCB banking as the main reason for this decision.

\section{Conclusion:}

The knowledge and awareness of UCB storage and banking possibilities amongst women in Poland could be improved. The professional medical personnel should be a source of reliable information.

Keywords: Cord blood stem cells, Umbilical cord blood, Umbilical cord blood banking, Women's knowledge 